\title{
On the Drivers of Decadal Variability of the Gulf Stream North Wall $\mathscr{O}$
}

\author{
Christopher L. P. Wolfe, Sultan HAMEed, AND LeQuan Chi \\ School of Marine and Atmospheric Sciences, Stony Brook University, State University of New York, Stony Brook, New York
}

(Manuscript received 6 April 2018, in final form 28 November 2018)

\begin{abstract}
The Gulf Stream is bounded to the north by a strong temperature front known as the North Wall. The North Wall is subject to variability on a wide range of temporal and spatial scales - on interannual time scales, the dominant mode of variability is a longitudinally coherent north-south migration. North Wall variability since 1970 has been characterized by regular oscillations with a period of approximately nine years. This periodic variability, and its relationship to major modes of Atlantic climate variability, is examined in the frequency domain. The North Atlantic Oscillation (NAO) and the Atlantic meridional mode (AMM) both covary with the North Wall on decadal time scales. The NAO leads the North Wall by about one year, whereas the covariability between the North Wall and the AMM is synchronous (no lag). Covariability between the North Wall and the NAO is further examined in terms of the centers of action comprising the NAO: the Icelandic low and Azores high. It is found that the strength of the Icelandic low and its latitude as well as the strength of the Azores high play a role in decadal North Wall variability.
\end{abstract}

\section{Introduction}

The dominant paradigm for interannual and decadal upper-ocean variability is based on the idea of stochastic climate variability. This paradigm was introduced by Hasselmann (1976) and Frankignoul and Hasselmann (1977), who envisioned oceanic variability driven by atmospheric forcing that is essentially random and white; that is, power is evenly distributed in frequency. Because of its large heat capacity, the ocean "reddens" the atmospheric forcing, resulting in pronounced low-frequency variability (e.g., Hasselmann 1976; Frankignoul and Hasselmann 1977; Frankignoul 1999). While forced from the surface, this stochastic variability can penetrate to depths below the main thermocline (Joyce and Robbins 1996; Frankignoul et al. 1997). This red noise paradigm is most successful when applied in the central and eastern parts of the major ocean basins. Variability in the western North Atlantic is dominated by the Gulf Stream, which is a discrete dynamical entity that integrates forcing perturbations over the entire tropical

Supplemental information related to this paper is available at the Journals Online website: https://doi.org/10.1175/JCLID-18-0212.s1.

Corresponding author: Christopher L.P. Wolfe, christopher.wolfe@ stonybrook.edu and subtropical North Atlantic and is subject to its own intrinsic multidecadal variability.

The Gulf Stream flows nearly parallel to the eastern North American coast until it reaches Cape Hatteras, North Carolina, where it detaches from the coast and flows northeastward as a free jet. The northern edge of the current is marked by a sharp temperature front, called the North Wall, which separates the waters of the Gulf Stream and Sargasso Sea to the south from the waters of the shelf and Slope Sea to the north (Fig. 1). While the point where the Gulf Stream diverges from the coast is remarkably stable (Chassignet and Marshall 2008), east of Cape Hatteras the latitude of the North Wall varies on time scales ranging from intraseasonal to decadal and longer (e.g., Taylor and Stephens 1980; Joyce et al. 2000; Molinari 2004; Rossby et al. 2010; Sasaki and Schneider 2011; Lillibridge and Mariano 2013).

Fluctuations in North Wall position have important consequences for regional climate because the Gulf Stream transports considerable heat from the ocean at low latitudes to the atmosphere at high latitudes (Johns et al. 2011). Rapidly deepening bomb cyclones tend to move along the axis of the Gulf Stream (Sanders 1986) and northward shifts of the Gulf Stream are associated with increased storminess in the northeastern United States (Joyce et al. 2009). The path of the Gulf Stream is important for marine biology, as it separates the cold, biologically productive slope water to the north from the 


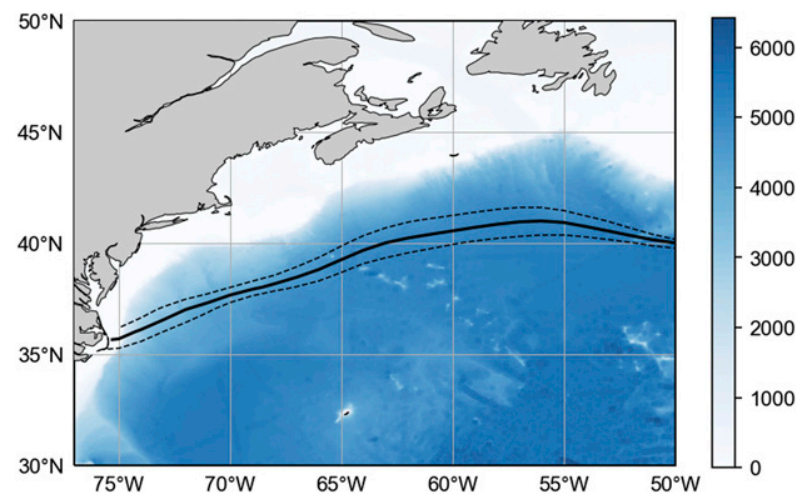

FIG. 1. Mean path of the $15^{\circ} \mathrm{C}$ isotherm at $200 \mathrm{~m}$ (solid) and the paths corresponding to GSI values of +2 and -2 standard deviations (northern and southern dashed lines, respectively); see section 1a for a description of the GSI. The shading gives depth in meters.

warm, less productive Sargasso Sea to the south (Nye et al. 2011).

On time scales of $1-5$ years, variations in North Wall position have been linked to atmospheric forcing in the form of large-scale climate modes such as the North Atlantic Oscillation (NAO; Taylor and Stephens 1998; Joyce et al. 2000; Frankignoul et al. 2001; Joyce et al. 2009) and El Niño-Southern Oscillation (ENSO; Taylor et al. 1998; Sanchez-Franks et al. 2016). A recent study by Hameed et al. (2018, hereafter HWC) made use of the extended observational record to examine the sources of North Wall variability in the time domain. They found that the dominant influence on the North Wall is from the Atlantic meridional mode (AMM), which is characterized by cross-equatorial SST gradients that are both driven by and sustain cross-equatorial winds (Nobre and Shulka 1996; Chang et al. 1997; Chiang and Vimont 2004). The mechanism proposed by HWC invokes the changes in the tropical wind field associated with the AMM. In particular, the positive phase of the AMM induces Ekman suction anomalies in the Caribbean Sea and western tropical Atlantic, which lead to a shoaling of the tropical thermocline. This shoaling signal is transferred to the Gulf Stream region with a delay of less than a year, causing the North Wall to move southward.

The purpose of this paper is to investigate the relationships of the Gulf Stream North Wall to the NAO and AMM in the frequency domain. The focus is on near-decadal time scales since the dominant time scale of North Wall variability is decadal. On these time scales, the North Wall exhibits a number of nearly oscillatory modes of variability. In particular, a quasi-decadal oscillation has been noted in both observational (Moron et al. 1998; Joyce et al. 2000; da Costa and de Verdiere 2002; Delworth et al. 2007; Nigam et al. 2018) and theoretical (Spall 1996; Marshall et al. 2001; Simonnet et al. 2003, 2005) studies. The reported period of this oscillation ranges from 7.5 to 13 years and several mechanisms have been put forth to explain it, including interaction with the deep western boundary current (DWBC) through eddy fluxes (Spall 1996), coupled atmosphere-ocean oscillations (Joyce et al. 2000; Marshall et al. 2001), and baroclinic instabilities of the wind-driven circulation (Simonnet et al. 2003, 2005). What is the source of this decadal variability? While intrinsic variability of the ocean circulation cannot be ruled out, observational evidence suggests that these fluctuations in position are at least partially driven by large-scale atmospheric or coupled ocean-atmosphere processes (e.g., Joyce et al. 2000; Frankignoul et al. 2001; Delworth et al. 2007; Nigam et al. 2018; HWC; as well as this study). Following HWC, we examine the role of the AMM and the NAO in the decadal variability of the North Wall. In addition, we consider the contributions of the component pressure centers of the NAO-the Icelandic low and the Azores high-to the variability of the North Wall.

The paper is organized as follows: The data and methods are described in section 2. North Wall variability and covariability with other climate indices in the time domain is briefly summarized in section 3 . Section 4 focuses on the frequency domain. Our results are compared to previous studies in section 5 and summarized in section 6 .

\section{Data and methods}

\section{a. Climate indices}

We make use of the common period 1961-2015 for all time series and consider either annual averages or an average over a single season. The time series are thus the same length $(N=55)$. Furthermore, all time series are linearly detrended prior to analysis to focus on decadalscale covariability.

\section{1) Gulf Stream North Wall}

Joyce et al. (2000) constructed an index of the Gulf Stream to represent the position of the North Wall. Specifically, this Gulf Stream index (GSI) is the principal component of the first EOF of 200-m temperature at nine points located along the mean position of the $15^{\circ} \mathrm{C}$ isotherm. While one would ideally track the position of the $15^{\circ} \mathrm{C}$ isotherm directly, locating a particular isotherm in a sparsely and unevenly sampled temperature field is challenging. The GSI is therefore based on temperature fluctuations at the mean position of the 
$15^{\circ} \mathrm{C}$ isotherm and uses the fact that these fluctuations are proportional to meridional excursions of the isotherm. The GSI used here is calculated in the same manner as Joyce et al. (2000) and Joyce et al. (2009) from temperature profiles obtained from the World Ocean Database (Boyer et al. 2013) and is available in the online supplemental material. We calculate GSI with an annual resolution over the time period 19542015. We only make use of GSI values starting in 1961 because of concerns about data sparseness in the early part of the record (i.e., 1954-60); we retain the earlier starting time (1954) to maintain consistency with original definition given by Joyce et al. (2000). Except where noted, the results are essentially unchanged if the early part of the record is retained.

Regressing the GSI against annual mean 200-m temperature from the gridded subsurface temperature dataset EN4.2.1 (Good et al. 2013; available at https:// www.metoffice.gov.uk/hadobs/en4) shows that the normalization of the GSI is such that values of +1 and -1 correspond to a northward and southward, respectively, displacement of $0.25^{\circ}$ between $70^{\circ}$ and $55^{\circ} \mathrm{W}$ (Fig. 1). The magnitude of the displacement is not uniform along the Gulf Stream path, but varies from a minimum of $0.13^{\circ}$ at $69^{\circ} \mathrm{W}$ to a maximum of $0.32^{\circ}$ at $58^{\circ} \mathrm{W}$. The total range of the GSI is approximately 4 , so the maximum excursion of the North Wall-averaged between $70^{\circ}$ and $55^{\circ} \mathrm{W}$-is approximately $1^{\circ}$.

The GSI, shown in Fig. 2a, has a significant $(p<0.05)$ linear trend of 0.42 decade $^{-1}$. Note that a basin-wide warming trend would cause the $15^{\circ} \mathrm{C}$ isotherm to migrate northward even if the North Wall itself remained stationary. It is therefore unlikely that the GSI trend represents a true northward migration of the North Wall-indeed, Bisagni et al. (2017) find that the Gulf Stream position (as detected by altimetry) has no significant trend, except at $55^{\circ} \mathrm{W}$ where the trend is southward. The time series additionally displays oscillations superimposed on the trend with a nearly decadal period. These decadal oscillations are fast compared to the global warming signal and thus likely represent true path shifts of the Gulf Stream.

\section{2) $\mathrm{AMM}$}

The Atlantic meridional mode is the dominant mode of atmosphere-ocean variability in the tropical Atlantic (Nobre and Shulka 1996; Chang et al. 1997). While Czaja et al. (2002) suggest that variations in tropical Atlantic SST are explained entirely by changes in the NAO and ENSO, Chiang and Vimont (2004) have argued convincingly that the AMM is sustained by coupling between the atmosphere and ocean with higher-latitude forcing representing high-frequency forcing. The AMM
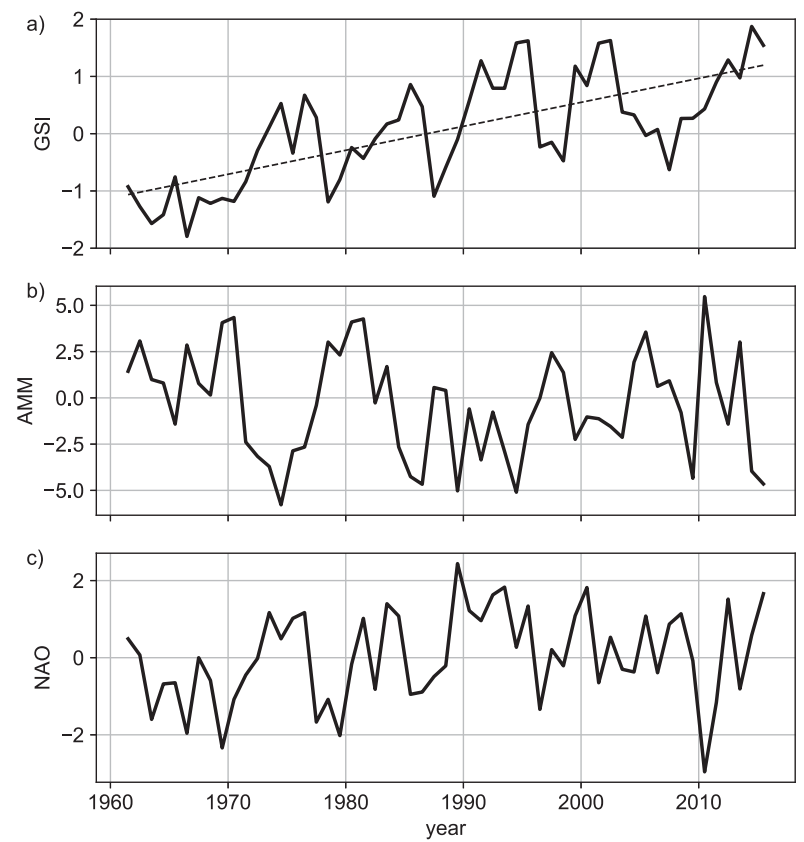

FIG. 2. Time series of the (a) GSI, (b) AMM, and (c) NAO. The dashed line in (a) gives the GSI trend of 0.42 decade $^{-1}$.

is characterized by an anomalous SST gradient across the mean latitude of the intertropical convergence zone with a cross-gradient atmospheric flow toward the warmer hemisphere [see Fig. 1 of Chiang and Vimont (2004) for an illustration of the AMM]. Anomalous wind stress on the sea surface leads to patterns of Ekman convergence and divergence that result in a temperature response at the depth of the tropical thermocline $(\sim 200 \mathrm{~m})$ that is opposite to the surface (HWC). In particular, the AMM winds cause the tropical thermocline to shoal in the North Atlantic during "high" years (i.e., years in which the tropical North Atlantic is warmer than the tropical South Atlantic).

The AMM index derives from a maximum covariance analysis of surface winds and SST in the tropical Atlantic Ocean (Chiang and Vimont 2004). The amplitudes of the resulting wind and SST patterns are represented by separate time series, with the wind and SST time series considered to be most representative of the forcing and coupled oscillation, respectively. The two time series are highly correlated $(r=0.82)$, but the SST time series has relatively more power at low frequencies (i.e., it is redder). Since we are concerned with the effect of the coupled oscillation on the North Wall, we make use of the SST time series. Most of the difference between the two time series is found at subdecadal frequencies, so the conclusions about decadal variability and covariability are unchanged if the wind series instead of the SST series is used. The SST time series is obtained from Vimont (2015). The AMM has its largest amplitude 
during the March-May (MAM) season, so we analyze averages over this season. The time series of MAM AMM values is shown in Fig. $2 b$.

\section{3) NAO}

The NAO is a leading mode of North Atlantic atmospheric variability, traditionally defined as the difference between sea level pressure anomalies measured in Iceland and the Azores (Hurrell 1995). The NAO has its greatest climatological influence during boreal winter [December-February (DJF)] and represents a simultaneous strengthening or weakening of the Icelandic low and Azores high, with concomitant fluctuations in the midlatitude westerly winds. This paper makes use of the NAO obtained by principal component analysis of DJF sea level pressure over North Atlantic, described by Hurrell et al. (2003) and downloaded from the National Center for Atmospheric Research (2017). The time series of the NAO is shown in Fig. 2c.

An alternate representation of NAO (the CPC NAO; Climate Prediction Center 2012) can be obtained by rotated principal component analysis of monthly mean $500-\mathrm{mb}$ heights over the region north of $20^{\circ} \mathrm{N}$. The loading pattern for the CPC NAO is concentrated in the North Atlantic and also has its largest amplitude in DJF. The two NAO indices are highly correlated $(r=0.88)$ and the results of this paper are unchanged if the Hurrell NAO index is replaced with the CPC NAO index.

\section{4) Centers of ACTION}

The atmospheric circulation in the mid- and high latitudes of the North Atlantic Ocean is dominated by the Icelandic low (IL) and the Azores high (AH)-these semipermanent highs and lows were referred to as "centers of action" by Rossby et al. (1939). Fluctuations in the strengths and positions of the Icelandic low and Azores high contribute to the NAO. Individual metrics of the Icelandic low and Azores high contain, in principle, more information than the NAO index since the NAO is a one-dimensional projection of the variability expressed by the Icelandic low and the Azores high. These semipermanent pressure centers are discrete dynamical objects that evolve according to their internal dynamics and external forcing. As such, indices representing fluctuations in their strength and position are more physically meaningful than the NAO index, which is obtained through dynamically blind statistical techniques.

Indices for the strength and position of the Icelandic low and Azores high are calculated according to Hameed and Piontkovski (2004) and are available from Hameed (2017). Similar to the NAO, the Icelandic low is strongest in winter. The annual cycle of Azores high pressure has two maxima: one in winter and the other during summer. However, the summertime maximum is extremely stable and contributes very little to the variance of the Azores high indices. Since we are considering the centers of action in the context of the NAO, we make use of the same seasonal average as the NAO (DJF) for the indices of both pressure centers.

The time series of DJF values of the center-of-action indices are shown in Fig. 3. Note that here and in all that follows, the sign of the Icelandic low pressure series has been reversed to facilitate comparison with the other center-of-action indices and the NAO. None of the Icelandic low indices have significant trends. In contrast, the Azores high is strengthening and moving eastward at rates of $0.26 \mathrm{mbdecade}^{-1}$ and $0.86^{\circ} \mathrm{decade}^{-1}$, respectively. All of the center-of-action indices are correlated with the NAO at zero lag, with Icelandic low latitude and Azores high pressure having the highest correlation and Icelandic low longitude the lowest correlation (Fig. 4). The center-of-action indices are additionally mutually correlated, with only three exceptions.

\section{b. Methods}

\section{1) Correlations}

Lagged correlations are calculated using the standard Pearson product-moment correlation (e.g., von Storch and Zwiers 1999, section 8.2 therein) with time-shifted time series. Significance of correlations is assessed using the random phase test of Ebisuzaki (1997), which accounts for serial correlation in the individual time series.

\section{2) Spectral AnAlysis}

Power spectra are calculated using the multitaper method (MTM) of Thomson (1982), as summarized in Percival and Walden (1993). The MTM produces a power spectrum with a frequency resolution of $\Delta f=2 p f_{R}$, where $f_{R}=(55 \mathrm{yr})^{-1}$ is the Rayleigh frequency and $p$ is the time-bandwidth parameter. We choose $p=2$ and use three tapers $(K=3)$; Ghil et al. (2002) note that this is an optimal choice for short climatic time series. All time series are linearly detrended, tapered, and zero padded to 8 times their original length to avoid spurious cyclical correlations prior to Fourier analysis. Doubling or halving the padding length has no effect on the results.

In addition to spectra, the multitaper method can be used to detect harmonic "lines"; that is, oscillations with nearly constant phase over the length of the time series. Putative lines are considered detected if they pass the Fisher-Snedecor test with 95\% confidence (for details see Thomson 1982; Percival and Walden 1993; Ghil et al. 2002). 

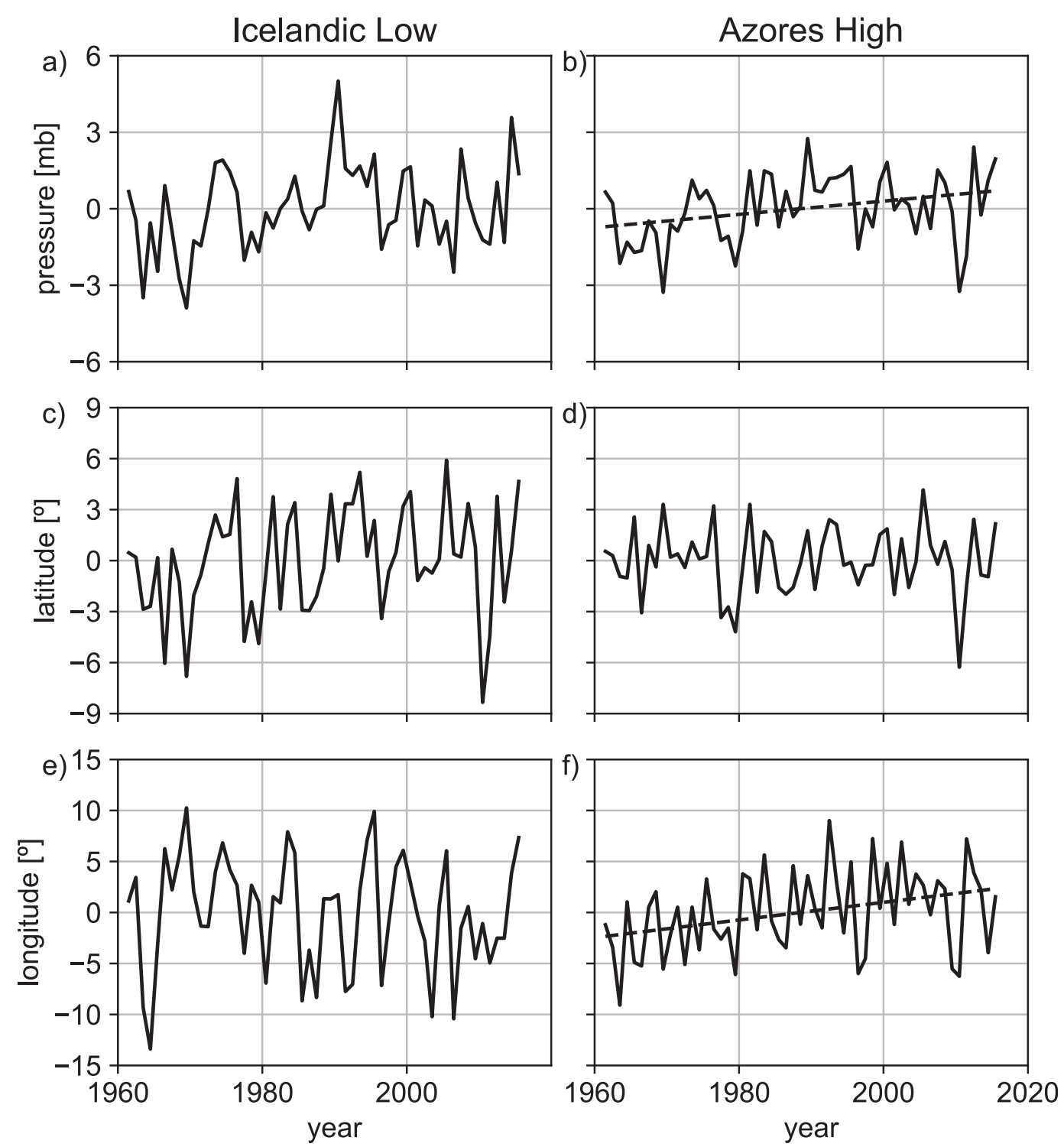

FIG. 3. Anomalous DJF values of (a),(b) pressure; (c),(d) latitude; and (e),(f) longitude for the (left) IL and (right) AH. Anomalies are relative to the 1961-2015 mean. Dashed lines in (b) and (f) give significant $(p<0.05)$ trends of $0.26 \mathrm{mb} \mathrm{decade}^{-1}$ and $0.86^{\circ} \mathrm{decade}^{-1}$, respectively. Note that the sign of the IL pressure series (a) has been reversed.

Confidence intervals are calculated using the fact that MTM spectral estimates are distributed like a $\chi^{2}$ random variable with approximately $2 K$ degrees of freedom. The effective degrees of freedom can be less than $2 K$ at frequencies with large taper-induced bias-these are usually frequencies with very low power. In addition to confidence intervals on the spectral estimates, for the purposes of detecting peaks it is useful to know if the spectral density at a given frequency is greater than expected based on the assumption that the underlying process is generated by atmospheric noise reddened by interaction with the ocean (e.g., Hasselmann 1976;
Frankignoul and Hasselmann 1977). The simplest and most frequently used red noise model is the first-order autoregressive process [AR(1)] spectrum, which is fit to an estimate of continuous spectrum of the time series via least squares regression.

The continuous spectrum of a time series is estimated in an iterative manner following the procedure of Mann and Lees (1996):

1) The MTM spectrum is smoothed using a median filter of width $2 p f_{R}$ and fit to a red noise spectrum using least squares regression. 


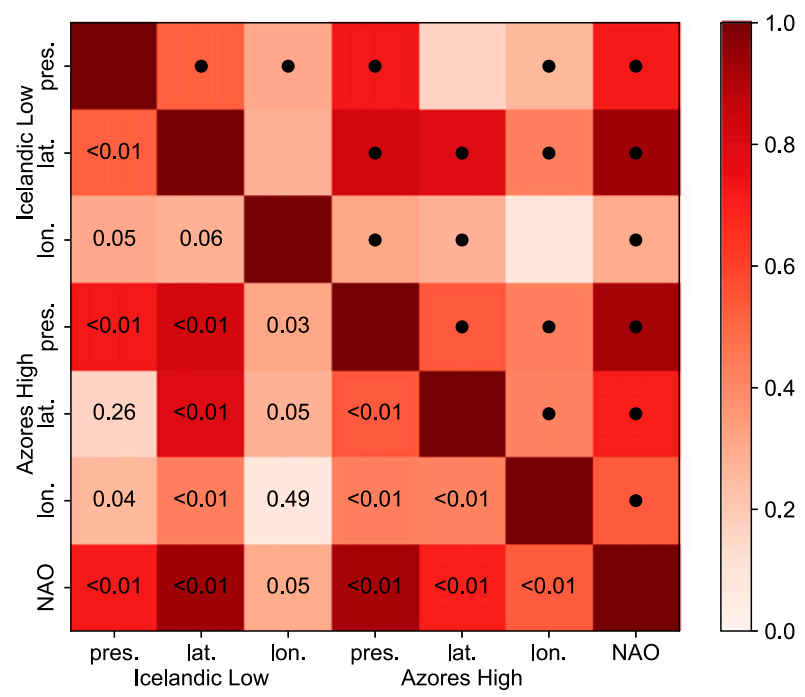

FIG. 4. Matrix of correlations between the center-of-action components and the NAO. Dots above the diagonal indicate significant correlations $(p<0.05)$ and numbers below give the $p$ value of the correlation. The sign of the IL pressure series has been reversed, so all of its correlations are negative.

2) Lines are detected by multitaper harmonic analysis. If the peak associated with the line passes the $\chi^{2}$ test relative to the red noise fit at $95 \%$ percent confidence, the line is removed and the spectrum reshaped.

Steps 1 and 2 are repeated until no significant lines remain. In the present case, a single iteration is sufficient to estimate the continuous spectrum and only the GSI spectrum contained a line of sufficient power to be removed. Note that power spectra are plotted with the lines retained; the removed lines only affect the estimate of the continuous spectrum.

\section{3) COHERENCE AND PHASE}

The MTM coherence and phase are calculated according to Thomson (1982). The critical value of the coherence $C_{\text {crit }}$ which is significantly different from zero at the $1-p$ confidence threshold is given by Amos and Koopmans (1963) as

$$
C_{\text {crit }}=1-p^{1 /(K-1)},
$$

where $K$ is the number of tapers used in the spectral estimate (see also Carter 1987). Following Bendat and Piersol (2010), confidence intervals for the phase are calculated by noting that phase estimates are approximately Gaussian distributed with variance,

$$
\operatorname{Var} \Phi_{x y}=\frac{1-C_{x y}}{2 K C_{x y}} .
$$

TABLE 1. Correlations of the indices of the IL and AH with the GSI. The columns give the correlation $r$ and the $p$ value when the GSI lags the center-of-action index by up to two years. Correlations significantly different from zero $(p<0.05)$ are indicated in bold. The sign of the IL

\begin{tabular}{|c|c|c|c|c|c|c|c|}
\hline & & \multicolumn{2}{|c|}{ Lag 0} & \multicolumn{2}{|c|}{ Lag 1} & \multicolumn{2}{|c|}{ Lag 2} \\
\hline & & $r$ & $p$ & $r$ & $p$ & $r$ & $p$ \\
\hline \multirow[t]{3}{*}{ IL } & Pressure & 0.41 & 0.01 & 0.51 & $<0.01$ & 0.37 & 0.04 \\
\hline & Latitude & 0.33 & 0.01 & 0.31 & 0.04 & 0.30 & 0.07 \\
\hline & Longitude & 0.19 & 0.17 & 0.25 & 0.04 & 0.20 & 0.12 \\
\hline \multirow[t]{3}{*}{$\mathrm{AH}$} & Pressure & 0.41 & $<0.01$ & 0.36 & 0.01 & 0.34 & 0.02 \\
\hline & Latitude & 0.18 & 0.08 & 0.10 & 0.41 & 0.17 & 0.18 \\
\hline & Longitude & 0.07 & 0.56 & 0.22 & 0.07 & 0.19 & 0.14 \\
\hline
\end{tabular}
pressure index has been reversed, so its correlations are actually negative.

\section{North Wall covariability in the time domain}

Here, we briefly summarize North Wall variability and covariability in the time domain. Correlations of the GSI with the NAO and AMM are discussed in HWC, to which the reader is referred for details. HWC found that both the NAO and the AMM series are correlated with the GSI for short positive lags (0-1 year); the correlation with the AMM is negative, meaning that the Gulf Stream moves south when the AMM index is high. They proposed that the negative correlation between the GSI and AMM was due to Ekman suction anomalies induced by the AMM in the Caribbean and tropical North Atlantic. The Ekman suction shoals the tropical thermocline, producing cold anomalies concentrated near 200-m depth. The thermocline height/temperature anomalies are carried into the Gulf Stream by advection in the Caribbean Sea and Gulf of Mexico and by a combination of advection and Rossby wave propagation in the North Equatorial Current.

Like the NAO, Icelandic low pressure and latitude and Azores high pressure are correlated with the GSI at lags of $0-1$ year (Table 1 ). The center-of-action indices are correlated with the NAO, so it is reasonable to expect that their correlations with the GSI are similar to those of the NAO. The centers of action also show correlations with the GSI not shared with the NAO: the two pressure indices are additionally correlated with the GSI at lags of two years, and Icelandic low longitude is weakly correlated with the GSI at a lag of one year. Hameed and Piontkovski (2004) and SanchezFranks et al. (2016) found similar correlations between the centers of action and the surface-based North Wall index of Taylor and Stephens (1980,1998), although they found the lag between Icelandic low longitude and the North Wall to be 3-4 years and a significant correlation between the North Wall and Azores high longitude with a lag of 2 years. HWC have shown that the GSI and surface-based indices of the 
North Wall respond differently to the NAO and AMM.

The AMM is significantly $(p<0.05)$ anticorrelated with the NAO at lags of zero and one year $(r=-0.45$ and $r=-0.40$, respectively), which is indicative of the role of the NAO in driving the AMM.

\section{North Wall variability and covariability in the frequency domain}

The investigation of North Wall covariability in the frequency domain focuses on near-decadal time scales. Most of the time series have peaks and covariability with the North Wall at higher frequencies $(f>0.2$ cpy), which, while intriguing, are not the subject of this study.

The spectrum of the GSI, shown in Fig. 5a, has a significant peak centered at frequency of $f_{0}=0.109$ cpy (period: 9.2 years). The frequency averaging inherent in the MTM gives a maximum frequency resolution of $2 p f_{R}=0.073 \mathrm{cpy}$, so the "true" period of the oscillation could fall anywhere in the interval 6.9-13.8 years. We refer to this interval as the "decadal band" and highlight it in subsequent figures. The power in the decadal band represents $43 \%$ of the total variance of the (detrended) GSI. The line test detects a harmonic line at $f_{0}=(9.2 \mathrm{yr})^{-1}$ at better than $95 \%$ confidence, suggesting that the decadal variability in the GSI from 1961 to 2015 is due to a single oscillation with nearly constant phase centered at $f_{0}$. The GSI spectrum has additional peaks at integer multiples of $f_{0}$ representing harmonics, although only the peak with $f=4 f_{0}$ is detected as a line.

Both the AMM series and NAO also have peaks in the decadal band, although the significance of these peaks is not as great as for the GSI. Power in the decadal band represents $36 \%$ and $31 \%$ of the total variance of the AMM and NAO, respectively. The AMM decadal peak is broader than the GSI's peak and not significantly stronger than one would expect for reddened atmospheric noise (Fig. 5b). The NAO's decadal peak is centered at slightly higher frequencies than that of the GSI or AMM (Fig. 5d). The high-frequency edge $^{1}$ (at a period of 7 years) of this peak is just significant at $95 \%$ confidence relative to red noise. Similar spectral peaks in the NAO at these frequencies have been noted previously (e.g., da Costa and de Verdiere 2002), with significant debate attached to whether these peaks represent truly periodic, deterministic behavior or

\footnotetext{
${ }^{1}$ Since the frequency resolution is $2 p f_{R}$, the "true" location of the peak may be at lower frequencies. We make use of frequency intervals smaller than $2 p f_{R}$ in the description of the spectra to help orient the reader.
}
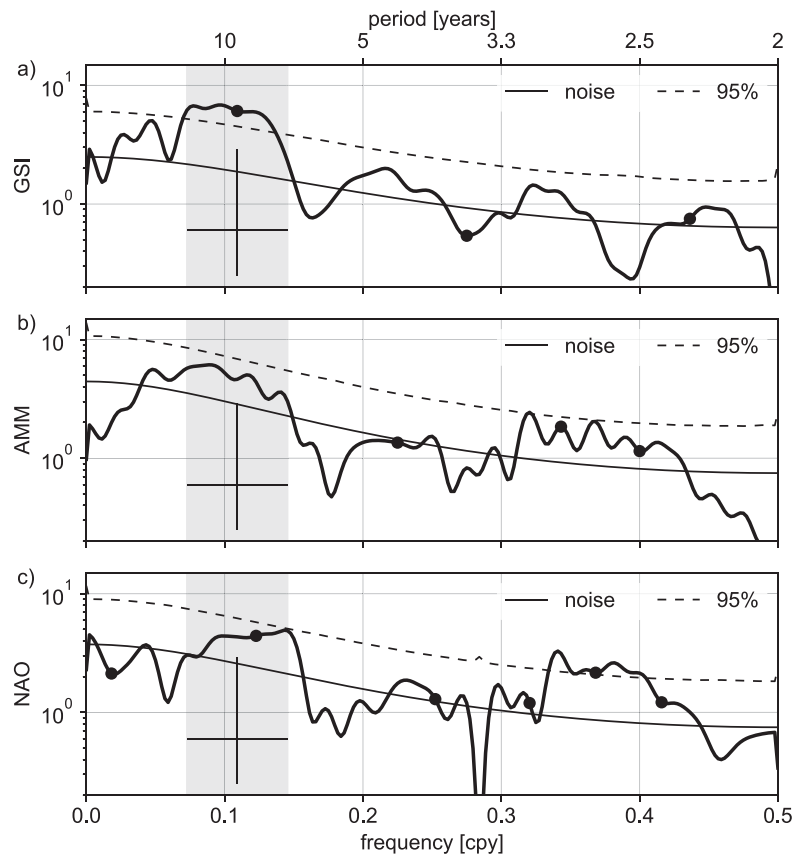

FIG. 5. Power spectra of the (a) GSI, (b) AMM, and (c) NAO as a function of frequency in cpy. Spectra have been normalized to have unit variance. The thin solid line gives the red noise model for the spectrum, and the dashed line gives the $95 \%$ significance level relative to the red noise fit. The vertical lines on the cross give the upper and lower $95 \%$ confidence interval of the spectral estimate, and the horizontal lines give the effective frequency resolution of the spectra $\Delta f=2 p f_{R}$. The shaded area is the decadal band, centered on $f=0.109$ cpy (9.2 years) with a width of $\Delta f$ (6.9-13.8 years). Harmonic lines are indicated by filled black circles.

whether they are artifacts resulting from the analysis of short records of essentially random phenomena (see, e.g., Wunsch 1999; Stephenson et al. 2000). We note that the line test detects a harmonic oscillation with a period of 8.1 years in the NAO, but acknowledge that such lines may very well arise randomly and the NAO is unlikely to have truly periodic variability on any time scale.

The spectra of the pressure and latitude indices of the centers of action are broadly similar to that of the NAO (Figs. 6a-d). They all have peaks in or near the decadal band, although only the peak for the Azores high latitude is significant relative to red noise. The fraction of variance captured by the decadal peaks is $\approx 30 \%$ for the Icelandic low pressure and latitude indices and $\approx 24 \%$ for the Azores high pressure and latitude indices. Three of the four indices also have harmonic lines in the decadal band at the same frequency as NAO's decadal line. The Azores high pressure spectrum lacks the harmonic line, but the 7-yr peak is more prominent than that of Icelandic low pressure (Figs. 6a,b). 


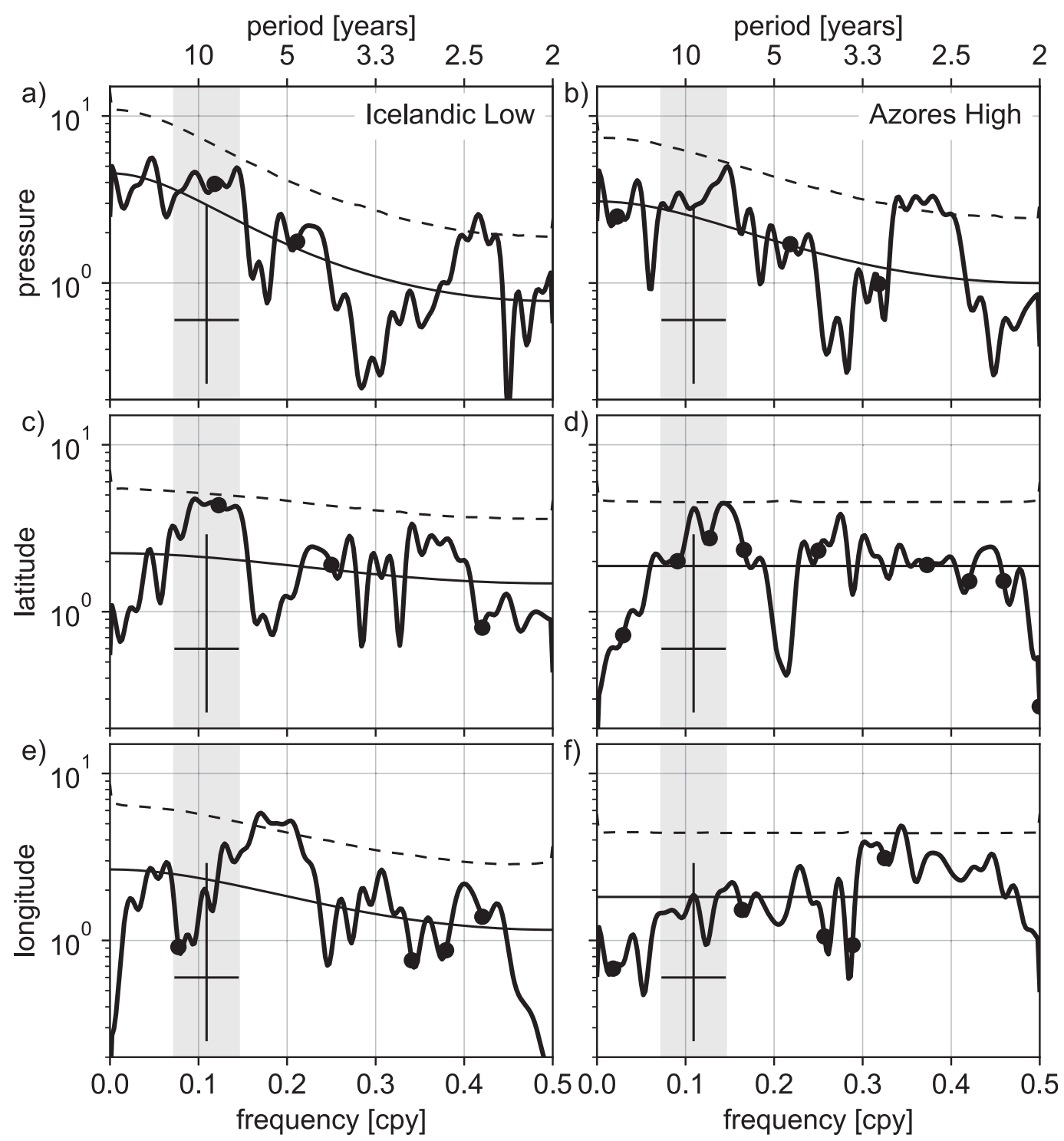

FIG. 6. As in Fig. 5, but for the (a),(b) pressure; (c),(d) latitude; and (e),(f) longitude indices of the (left) IL and (right) $\mathrm{AH}$.

In contrast, neither of the longitude spectra closely resemble the spectrum of the NAO, and they both lack peaks in the decadal band. The spectrum of Icelandic low longitude has a prominent (and significant) maximum with periods in the range of 5-6 years, giving it a slightly reddened spectrum. In contrast, the spectrum of Azores high longitude is nearly white with significant power only at periods of less than 3.3 years.

The AMM and NAO are coherent with the GSI in the decadal band (Figs. 7a,b). The coherence of the AMM and NAO with the GSI is likely not due to the coherence between the AMM and the NAO, which is only significant at periods near 5 years and longer than 17 years (Fig. 8). The phase lag between the AMM and GSI is close to $180^{\circ}$ throughout the decadal band, ${ }^{2}$ meaning that the two time series covary synchronously with a sign change (Fig. 7c). This covariability is also evident in the time domain, corresponding to a negative correlation between the two time series at zero lag. HWC show that the GSI responds to Ekman suction anomalies

\footnotetext{
${ }^{2}$ Since the time series are coherent in very narrow frequency bands (typically with a width comparable to the Rayleigh frequency), we interpret the coherence as due to a small number of phase-locked oscillations. The phase therefore represents the phase delay at that frequency. If, on the other hand, coherence were observed over a contiguous range of frequencies, then the delay between the two signals would be given by the slope of the phase plot.
} 


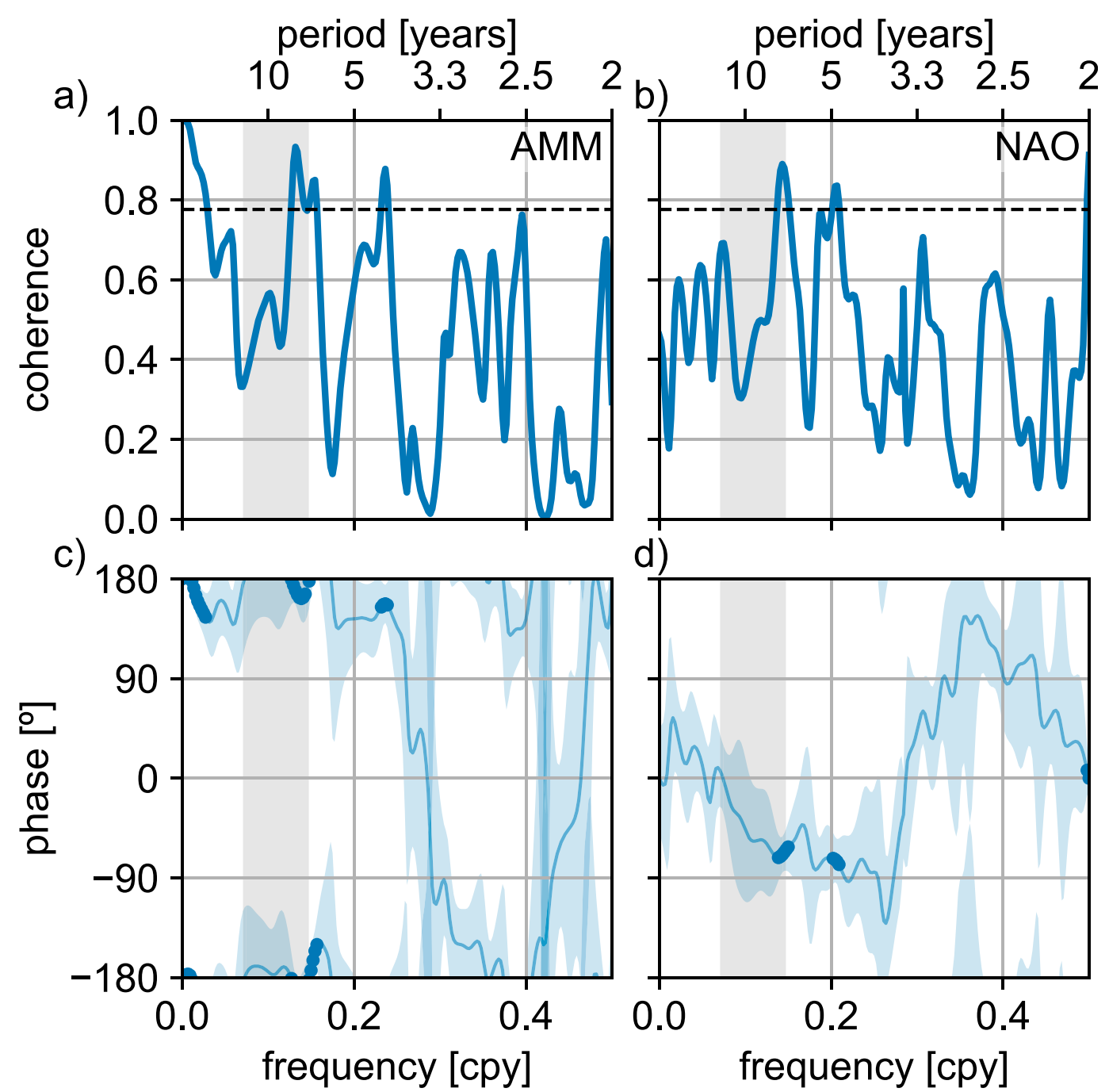

FIG. 7. (a),(b) Mean-squared coherence and (c),(d) phase between GSI and (left) AMM and (right) NAO; values above the dashed line are significantly greater than zero at the $95 \%$ confidence level. The phase and its $95 \%$ confidence interval are indicated for all frequencies in pale blue; those corresponding to frequencies with significant coherence are shown in dark blue. The shaded interval is the GSI decadal band indicated in Fig. 5.

produced by the AMM in the tropical North Atlantic that propagate into the Gulf Stream region within a year.

The phase lag between the NAO and GSI is approximately $-65^{\circ}$ in the decadal band, which means that the NAO leads the GSI by approximately one year (Fig. 7d). The lead-lag relationship is also apparent from careful visual inspection of their time series (Figs. 2a,c). Note that the use of seasonal and annual averages means that fractional-year lags are not meaningful.

Icelandic low pressure and latitude are coherent with the GSI in the decadal band near the same frequency band and with the same phase as the NAO (Fig. 9). In contrast, Icelandic low longitude displays a remarkable lack of coherence with the GSI in the decadal band-the variability of two time series is therefore unrelated on decadal time scales. Only the pressure index of the Azores high is coherent with the GSI in the decadal band (Fig. 10), also with the same phase as the NAO. The value of the coherence is just above the $95 \%$ significance threshold and becomes insignificant if the time period is shifted slightly to 19542012. This suggests that the coherence between the GSI and Azores high pressure is not robust. The decadal covariability between the NAO and the GSI is thus due primarily to fluctuations in Icelandic low pressure and latitude, with a possible contribution from the Azores high pressure.

\section{Discussion}

While the connection between the AMM and the Gulf Stream has only been noted in one previous study 

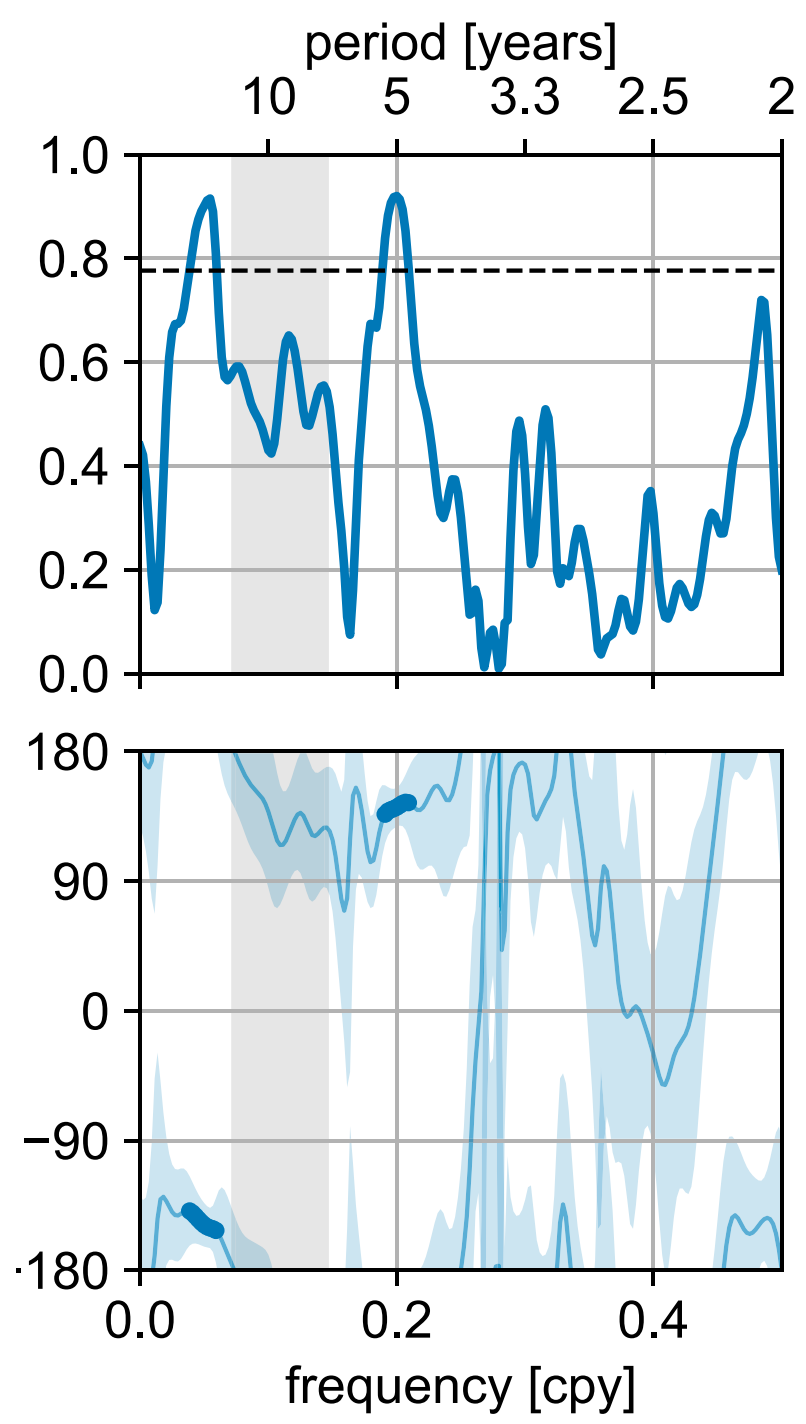

FIG. 8. As in Fig. 7, but between the AMM and NAO.

(HWC), the decadal variability of the Gulf Stream and its interaction with the NAO has a long history and requires further discussion.

A decadal-scale oscillation involving the Gulf Stream has been found by several previous studies that primarily made use of surface data. Moron et al. (1998) report two oscillations in SST that involve the Gulf Stream: a 7-8-yr oscillation attributed to fluctuations in the strength of the subtropical/subpolar gyre system and a 13-15-yr oscillation involving advection of SST anomalies by the Gulf Stream and North Atlantic Current. Da Costa and de Verdiere (2002) find a 7.7-yr oscillation and Watanabe et al. (1999) find a 12.3-yr oscillation, also in SST. The long and short oscillations found in these studies are similar to the long and short oscillations reported by Moron et al. (1998). Evidence for the longer oscillation, with reported periods of 12-14 years, is also found in SST averaged along the Gulf Stream path (Sutton and Allen 1997) and sea level data (Häkkinen 2000). The shorter oscillation in the GSI was noted by Joyce et al. (2000), who used subsurface temperature data, although their time series was too short to quantify its period and statistical significance. While both the long and short oscillations are in or near the decadal band defined in the present study, the detection of a single harmonic line at 9.2 years suggests a singlefrequency oscillation. The appearance of a second period in studies based on surface data suggests that the second oscillation may be restricted to the surface layer. Alternately, the single period found here and by Joyce et al. (2000) may be variously detected at higher or lower frequencies depending on the data analyzed and analysis technique employed, leading to the spurious appearance of a second oscillation.

Much attention has been focused on the effect of the NAO on the Gulf Stream, with most studies finding a 1-1.5-yr lag between the NAO and Gulf Stream migration (Curry and McCartney 2001; Frankignoul et al. 2001; Watelet et al. 2017; Nigam et al. 2018), although some find shorter lags of 0-1 years (Joyce et al. 2000; Pérez-Hernández and Joyce 2014; HWC), while others report a 2-yr lag (Taylor and Stephens 1998; Sasaki and Schneider 2011). Sanchez-Franks et al. (2016) spans these estimates with significant correlations between the Gulf Stream and NAO with lags of $0-2$ years. Reasons for the differences in the reported lags include the use of surface data versus subsurface data, the use of different indices of Gulf Stream position, as well as the use of different averaging periods for the NAO and Gulf Stream data; the differences between the reported lags are therefore unlikely to be significant. The present observation of a 1-yr lag in the decadal band suggests that the lags noted in these previous studies are due, in part, to covariability in the decadal band.

The mechanism for the NAO's influence on the Gulf Stream has been ascribed to long Rossby waves generated by anomalous Ekman convergence (e.g., Gangopadhyay et al. 1992; Taylor and Gangopadhyay 2001; Sasaki and Schneider 2011). Marshall et al. (2001) use this idea to propose a delayed oscillator model that gives coupled oscillations of the Gulf Stream and the NAO with periods near 10 years, although the lag between the NAO and the Gulf Stream-set by the propagation time for long Rossby waves at the latitude of the North Atlantic Current-is several times longer than the observed $1-1.5$ years. This long delay is due to the slow propagation speed of baroclinic Rossby waves and is a feature of all Rossby-wave-based mechanisms. Even at the 


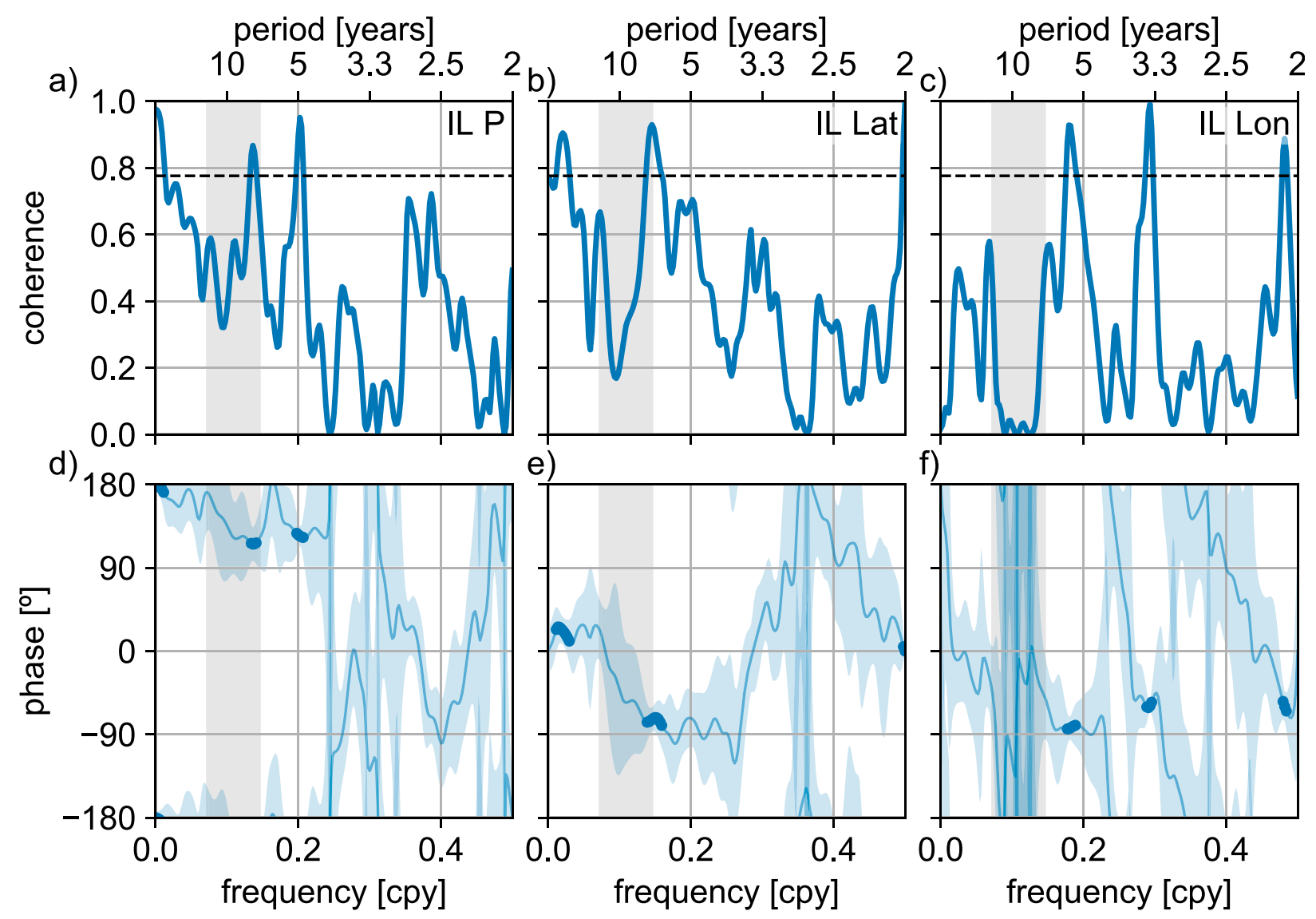

FIG. 9. As in Fig. 7, but between GSI and IL (left) pressure, (middle) latitude, and (right) longitude.

latitude of the Gulf Stream, where wave speeds are faster, the time for a Rossby wave generated in the eastern Atlantic, where the direct influence of the NAO on winds is concentrated, is 4-9 years (phase speeds taken from Killworth et al. 1997). Even if the waves were generated in the mid-Atlantic, the crossing time would still be $2-4.5$ years. This long crossing time inevitably gives lags between the NAO and Gulf Stream in excess of those observed. Further, Watanabe et al. (1999) find eastward propagation of temperature anomalies in the upper $100 \mathrm{~m}$ in the subtropical North Atlantic, which is inconsistent with Rossby wave propagation.

What, then, is the nature of the connection between the NAO and the Gulf Stream? Joyce et al. (2000) proposed a simple coupled model for the oscillation whereby changes in the position of the Gulf Stream cause shifts in the North Atlantic storm track. These atmospheric changes affect the rate of deep water formation in the Labrador Sea leading to changes in transport in the DWBC. Since the speed of the DWBC is $5-10 \mathrm{~cm} \mathrm{~s}^{-1}$, the transit time for anomalies from the Labrador Sea (a distance of $3000-4500 \mathrm{~km}$ ) is 1-2 years, which is consistent with the lags reported here and elsewhere. However, the studies of Bower et al. (2009) and Bower et al. (2011) have shown that a significant fraction of the water exported from the Labrador Sea does not enter the DWBC, but instead follows interior pathways as it flows southward. It therefore seems unlikely that there exists a direct correspondence between deep water formation rates in the Labrador Sea and the transport of the DWBC.

An alternative connection between the Labrador Sea and the Gulf Stream was proposed by Rossby (1999), who suggested that variations in the southward transport of water from the Labrador Current into the Slope Sea are the primary determinant of changes in the Gulf Stream's position. The transport of Labrador Slope Water along the shelf break is negatively correlated with the NAO (Pickart et al. 1999; Rossby and Benway 2000), since cold winters (high NAO) favor the formation of intermediate water that subducts and is exported eastward after passing the Grand Banks, rather than remaining near the shelf (Rossby and Benway 2000; Smith et al. 2001; Rossby et al. 2005). Changes in Labrador Current transport thus lead to changes in Slope Sea 

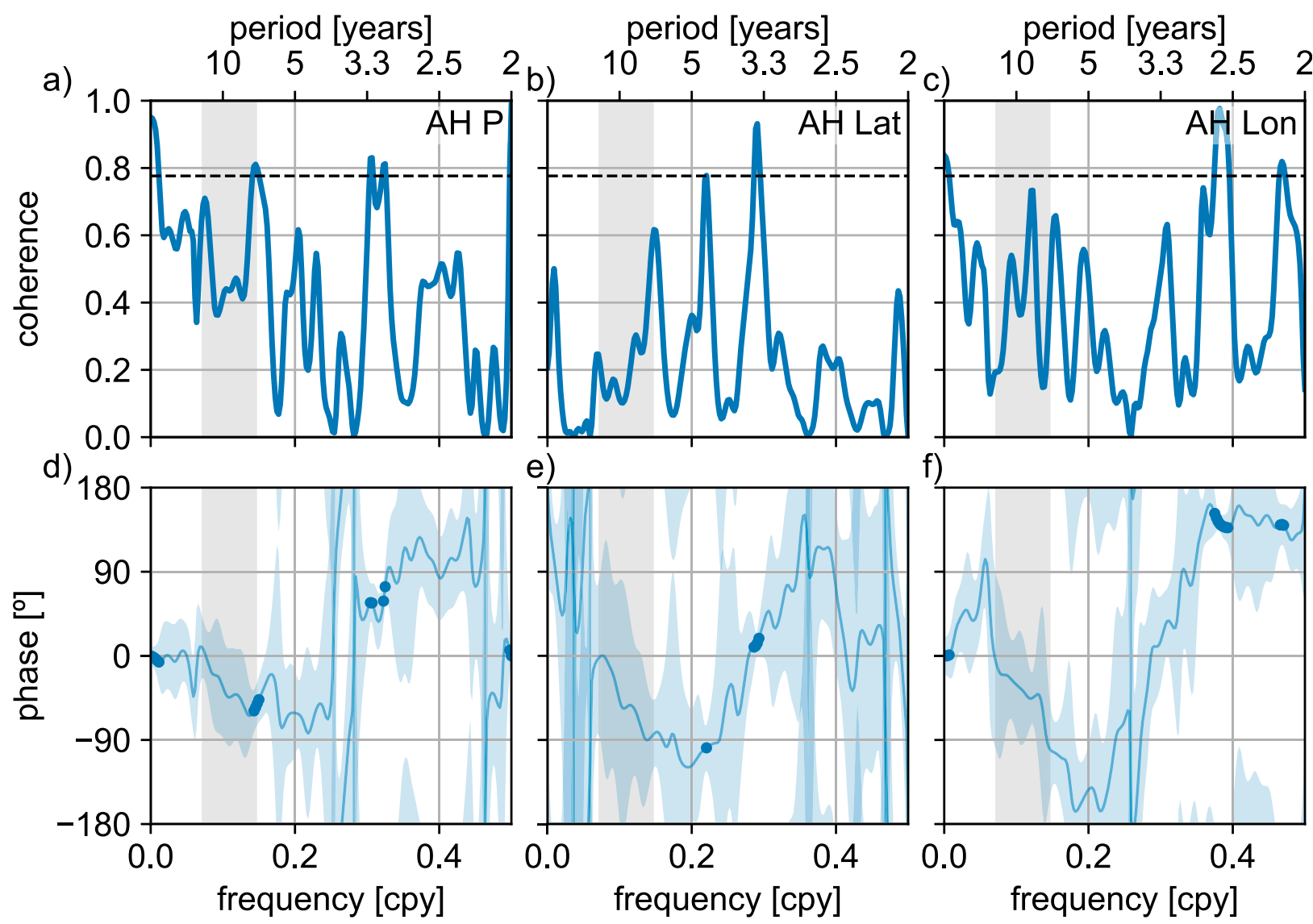

FIG. 10. As in Fig. 7, but between GSI and AH (left) pressure, (middle) latitude, and (right) longitude.

temperature and salinity, which then cause shifts in the Gulf Stream. Peña-Molino and Joyce (2008) also implicated the Slope Sea in Gulf Stream shifts, and Bisagni et al. (2017) have noted correlations between the Gulf Stream position and the transport of Labrador Current around the Grand Banks. Nigam et al. (2018) further show that northward Gulf Stream shifts are preceded by a cooling of the Labrador Current, which they ascribe, ultimately, to anomalous coastal upwelling along the west coast of Greenland.

The fact that we find that Icelandic low pressure and latitude are coherent with the GSI in the same frequency band and with the same phase as the NAO suggests that the primary influence of the NAO on the Gulf Stream is through the Icelandic low, with a possible contribution from Azores high pressure. This lends support to the idea that the connection between the NAO and the Gulf Stream is mostly in the north and is consistent with the regression studies of Hameed and Piontkovski (2004) and Sanchez-Franks et al. (2016), who used the surfacebased index of Taylor and Stephens $(1980,1998)$. Note, however, that Hameed and Piontkovski (2004) found Icelandic low longitude to be the dominant influence on the North Wall. While there is coherent variation between the GSI and Icelandic low longitude at higher frequencies, wintertime variations of Icelandic low longitude appear to play no direct role in the decadal variability of the GSI.

\section{Summary}

We report a decadal-scale oscillation in the latitude of the Gulf Stream North Wall. This oscillation has a period of 6.9-13.8 years and an amplitude of approximately $0.5^{\circ}$ in latitude. Harmonic analysis suggests that decadal variability is due to a single phase-coherent oscillation with a period of 9.2 years. Both the AMM series and the NAO have enhanced power in the decadal band. The pressure and latitude spectra of Icelandic low and Azores high all resemble the NAO, but their longitude spectra show marked differences.

Gulf Stream variability in the decadal band is related to both the AMM and the NAO. The covariability between the Gulf Stream and the AMM is synchronous up to a sign change (the Gulf Stream moves north when the AMM index is low). HWC show the rapid response of 
the Gulf Stream to the AMM is due to the rapid adjustment of the northern tropical Atlantic, which contains the source waters of Gulf Stream. In contrast, the decadal variability of the Gulf Stream lags the NAO by about one year. The short lag suggests that Rossby wave propagation is not responsible for the covariability between the NAO and the Gulf Stream. However, this lag is consistent with mechanisms invoking the Labrador Sea as the mediator of covariability between the Gulf Stream and the NAO.

NAO and Icelandic low pressure and latitude are coherent with GSI in the same frequency band and with the same lag. Azores high pressure is also coherent with the GSI, although the value of the coherence is smaller. These results are again consistent with the idea that the NAO's influence on the Gulf Stream is primarily due to the NAO's impact on the Labrador Sea (as suggested by Rossby 1999; Joyce et al. 2000; Bisagni et al. 2017; Nigam et al. 2018 and others).

Acknowledgments. This work was supported by the National Science Foundation (OCE-1634829). The suggestions of three anonymous reviewers led to substantial improvements of this paper.

\section{REFERENCES}

Amos, D. E., and L. H. Koopmans, 1963: Tables of the distribution of the coefficient of coherence for stationary bivariate Gaussian processes. Sandia Corporation Monogr. SCR-483, 327 pp.

Bendat, J. S., and A. G. Piersol, 2010: Random Data: Analysis and Measurement Procedures. 4th ed., John Wiley and Sons, $640 \mathrm{pp}$.

Bisagni, J. J., A. Gangopadhyay, and A. Sanchez-Franks, 2017: Secular change and inter-annual variability of the Gulf Stream position, 1993-2013, 70-55 W. Deep-Sea Res. I, 125, 1-10, https://doi.org/10.1016/j.dsr.2017.04.001.

Bower, A. S., M. S. Lozier, S. F. Gary, and C. W. Böning, 2009: Interior pathways of the North Atlantic meridional overturning circulation. Nature, 459, 243-247, https://doi.org/ 10.1038/nature07979.

,$- \ldots$, and — 2011: Export of Labrador Sea Water from the subpolar North Atlantic: A Lagrangian perspective. Deep-Sea Res. II, 58, 1798-1818, https://doi.org/10.1016/j.dsr2.2010.10.060.

Boyer, T. P., and Coauthors, 2013: World Ocean Database 2013. NOAA Atlas NESDIS 72, 209 pp., https://doi.org/10.7289/ V5NZ85MT.

Carter, G. C., 1987: Coherence and time delay estimation. Proc. IEEE, 75, 236-255, https://doi.org/10.1109/PROC.1987.13723.

Chang, P., L. Ji, and H. Li, 1997: A decadal climate variation in the tropical Atlantic Ocean from thermodynamic air-sea interactions. Nature, 385, 516-518, https://doi.org/10.1038/ $385516 \mathrm{a} 0$

Chassignet, E. P., and D. P. Marshall, 2008: Gulf Stream separation in numerical ocean models. Ocean Modeling in an Eddying Regime, Geophys. Monogr., Vol. 177, Amer. Geophys. Union, 39-61, https://doi.org/10.1029/177GM05.
Chiang, J. C. H., and D. J. Vimont, 2004: Analogous Pacific and Atlantic meridional modes of tropical atmosphere-ocean variability. J. Climate, 17, 4143-4158, https://doi.org/10.1175/JCLI4953.1.

Climate Prediction Center, 2012: North Atlantic Oscillation. National Weather Services, accessed 2 June 2017, http:// www.cpc.ncep.noaa.gov/data/teledoc/nao.shtml.

Curry, R. G., and M. S. McCartney, 2001: Ocean gyre circulation changes associated with the North Atlantic Oscillation. J. Phys. Oceanogr., 31, 3374-3400, https://doi.org/10.1175/ 1520-0485(2001)031<3374:OGCCAW > 2.0.CO;2.

Czaja, A., P. van der Vaart, and J. Marshall, 2002: A diagnostic study of the role of remote forcing in tropical Atlantic variability. J. Climate, 15, 3280-3290, https://doi.org/10.1175/15200442(2002)015<3280:ADSOTR >2.0.CO;2.

da Costa, E. D., and A. C. de Verdiere, 2002: The 7.7-year North Atlantic Oscillation. Quart. J. Roy. Meteor. Soc., 128, 797-817, https://doi.org/10.1256/0035900021643692.

Delworth, T. L., R. Zhang, and M. E. Mann, 2007: Decadal to centennial variability of the Atlantic from observations and models. Ocean Circulation: Mechanisms and Impacts, Geophys. Monogr., Vol. 173, Amer. Geophys. Union, 131-148, https://doi.org/10.1029/173GM10.

Ebisuzaki, W., 1997: A method to estimate the statistical significance of a correlation when the data are serially correlated. J. Climate, 10, 2147-2153, https://doi.org/10.1175/1520-0442 (1997)010<2147:AMTETS>2.0.CO;2.

Frankignoul, C., 1999: Sea surface temperature variability in the North Atlantic: Monthly to decadal time scales. Beyond El Niño: Decadal and Interdecadal Climate Variability, A. Navarra, Ed., Springer-Verlag, 25-48.

__ and K. Hasselmann, 1977: Stochastic climate models, part II application to sea-surface temperature anomalies and thermocline variability. Tellus, 29, 289-305, https://doi.org/10.3402/ tellusa.v29i4.11362.

, P. Müller, and E. Zorita, 1997: A simple model of the decadal response to the ocean to stochastic wind forcing. J. Phys. Oceanogr., 27, 1533-1546, https://doi.org/10.1175/1520-0485 (1997)027<1533:ASMOTD>2.0.CO;2.

—, G. de Coëtlogon, T. M. Joyce, and S. Dong, 2001: Gulf Stream variability and ocean-atmosphere interactions. J. Phys. Oceanogr., 31, 3516-3529, https://doi.org/10.1175/15200485(2002)031<3516:GSVAOA > 2.0.CO;2.

Gangopadhyay, A., P. Cornillon, and D. R. Watts, 1992: A test of the Parsons-Veronis hypothesis on the separation of the Gulf Stream. J. Phys. Oceanogr., 22, 1286-1301, https://doi.org/ 10.1175/1520-0485(1992)022<1286:ATOTPH > 2.0.CO;2.

Ghil, M., and Coauthors, 2002: Advanced spectral methods for climatic time series. Rev. Geophys., 40, RG1003, https://doi.org/ 10.1029/2000RG000092.

Good, S. A., M. J. Martin, and N. A. Rayner, 2013: EN4: Quality controlled ocean temperature and salinity profiles and monthly objective analyses with uncertainty estimates. J. Geophys. Res. Oceans, 118, 6704-6716, https://doi.org/10.1002/ 2013JC009067.

Häkkinen, S., 2000: Decadal air-sea interaction in the North Atlantic based on observations and modeling results. J. Climate, 13, 1195-1219, https://doi.org/10.1175/1520-0442 (2000)013<1195:DASIIT > 2.0.CO;2.

Hameed, S., 2017: Atmospheric centers of action indices. Stony Brook University, accessed 25 July 2017, https://you.stonybrook. edu/coaindices.

, and S. Piontkovski, 2004: The dominant influence of the Icelandic low on the position of the Gulf Stream northwall. 
Geophys. Res. Lett., 31, L09303, https://doi.org/10.1029/ 2004GL019561.

_ C. L. P. Wolfe, and L. Chi, 2018: Impact of the Atlantic meridional mode on Gulf Stream North Wall position. J. Climate, 31, 8875-8894, https://doi.org/10.1175/JCLI-D-18-0098.1.

Hasselmann, K., 1976: Stochastic climate models part I. Theory. Tellus, 28, 473-485, https://doi.org/10.3402/tellusa.v28i6.11316.

Hurrell, J. W., 1995: Decadal trends in the North Atlantic Oscillation: Regional temperatures and precipitation. Science, $\mathbf{2 6 9}$, 676-679, https://doi.org/10.1126/science.269.5224.676.

_- Y. Kushnir, G. Ottersen, and M. Visbeck, 2003: An overview of the North Atlantic Oscillation. The North Atlantic Oscillation: Climatic Significance and Environmental Impact, Geophys. Monogr., Vol. 134, Amer. Geophys. Union, 1-35, https://doi.org/10.1029/134GM01.

Johns, W. E., and Coauthors, 2011: Continuous, array-based estimates of Atlantic Ocean heat transport at $26.5^{\circ} \mathrm{N}$. J. Climate, 24, 2429-2449, https://doi.org/10.1175/2010JCLI3997.1.

Joyce, T. M., and P. Robbins, 1996: The long-term hydrographic record at Bermuda. J. Climate, 9, 3121-3131, https://doi.org/ 10.1175/1520-0442(1996)009<3121:TLTHRA $>2.0$. CO;2.

— C. C. Deser, and M. A. Spall, 2000: The relation between decadal variability of subtropical mode water and the North Atlantic Oscillation. J. Climate, 13, 2550-2569, https://doi.org/ 10.1175/1520-0442(2000)013<2550:TRBDVO > 2.0.CO;2.

_- Y.-O. Kwon, and L. Yu, 2009: On the relationship between synoptic wintertime atmospheric variability and path shifts in the Gulf Stream and the Kuroshio Extension. J. Climate, 22, 3177-3192, https://doi.org/10.1175/2008JCLI2690.1.

Killworth, P. D., D. B. Chelton, and R. A. de Szoeke, 1997: The speed of observed and theoretical long extratropical planetary waves. J. Phys. Oceanogr., 27, 1946-1966, https://doi.org/ 10.1175/1520-0485(1997)027<1946:TSOOAT>2.0.CO;2.

Lillibridge, J. L., III, and A. J. Mariano, 2013: A statistical analysis of Gulf Stream variability from $18+$ years of altimetry data. Deep-Sea Res. II, 85, 127-146, https://doi.org/10.1016/ j.dsr2.2012.07.034.

Mann, M. E., and J. M. Lees, 1996: Robust estimation of background noise and signal detection in climatic time series. Climatic Change, 33, 409-445, https://doi.org/10.1007/BF00142586.

Marshall, J., H. Johnson, and J. Goodman, 2001: A study of the interaction of the North Atlantic Oscillation with ocean circulation. J. Climate, 14, 1399-1421, https://doi.org/10.1175/ 1520-0442(2001)014<1399:ASOTIO>2.0.CO;2.

Molinari, R. L., 2004: Annual and decadal variability in the western subtropical North Atlantic: Signal characteristics and sampling methodologies. Prog. Oceanogr., 62, 33-66, https://doi.org/ 10.1016/j.pocean.2004.07.002.

Moron, V., R. Vautard, and M. Ghil, 1998: Trends, interdecadal and interannual oscillations in global sea-surface temperatures. Climate Dyn., 14, 545-569, https://doi.org/10.1007/ s003820050241.

National Center for Atmospheric Research, 2017: The Climate Data Guide: Hurrell North Atlantic Oscillation (NAO) Index (PC-based). NCAR, accessed 18 February 2018, https:// climatedataguide.ucar.edu/climate-data/hurrell-north-atlanticoscillation-nao-index-pc-based.

Nigam, S., A. Ruiz-Barradas, and L. Chafik, 2018: Gulf Stream excursions and sectional detachments generate the decadal pulses in the Atlantic multidecadal oscillation. J. Climate, 31, 2853-2870, https://doi.org/10.1175/JCLI-D-17-0010.1.

Nobre, P., and J. Shulka, 1996: Variations of sea surface temperature, wind stress, and rainfall over the tropical Atlantic and
South America. J. Climate, 9, 2464-2479, https://doi.org/ 10.1175/1520-0442(1996)009<2464:VOSSTW>2.0.CO;2.

Nye, J. A., T. M. Joyce, Y.-O. Kwon, and J. S. Link, 2011: Silver hake tracks changes in northwest Atlantic circulation. Nat. Commun., 2, 412, https://doi.org/10.1038/ncomms1420.

Peña-Molino, B., and T. M. Joyce, 2008: Variability in the slope water and its relation to the Gulf Stream path. Geophys. Res. Lett., 35, L03606, https://doi.org/10.1029/2007GL032183.

Percival, D. B., and A. T. Walden, 1993: Spectral Analysis for Physical Applications. Cambridge University Press, 583 pp.

Pérez-Hernández, M. D., and T. M. Joyce, 2014: Two modes of Gulf Stream variability revealed in the last two decades of satellite altimeter data. J. Phys. Oceanogr., 44, 149-163, https:// doi.org/10.1175/JPO-D-13-0136.1.

Pickart, R. S., T. K. McKee, D. J. Torres, and S. A. Harrington, 1999: Mean structure and interannual variability of the slopewater system south of Newfoundland. J. Phys. Oceanogr., 29, 2541-2558, https://doi.org/10.1175/1520-0485(1999)029<2541: MSAIVO $>2.0 . \mathrm{CO} ; 2$.

Rossby, C.-G., and Coauthors, 1939: Relation between variations in the intensity of the zonal circulation of the atmosphere and the displacements of the semi-permanent centers of action. J. Mar. Res., 2, 38-55, https://doi.org/10.1357/002224039806649023.

Rossby, T., 1999: On gyre interactions. Deep-Sea Res. II, 46, 139-164, https://doi.org/10.1016/S0967-0645(98)00095-2.

, and R. L. Benway, 2000: Slow variations in mean path of the Gulf Stream east of Cape Hatteras. Geophys. Res. Lett., 27, 117-120, https://doi.org/10.1029/1999GL002356.

_ C. N. Flagg, and K. Donohue, 2005: Interannual variations in upper-ocean transport by the Gulf Stream and adjacent waters between New Jersey and Bermuda. J. Mar. Res., 63, 203-226, https://doi.org/10.1357/0022240053693851.

,$- \ldots$, and,- 2010 : On the variability of Gulf Stream transport from seasonal to decadal timescales. J. Mar. Res., 68 , 503-522, https://doi.org/10.1357/002224010794657128.

Sanchez-Franks, A., S. Hameed, and R. E. Wilson, 2016: The Icelandic low as a predictor of the Gulf Stream North Wall position. J. Phys. Oceanogr., 46, 817-826, https://doi.org/10.1175/ JPO-D-14-0244.1.

Sanders, F., 1986: Explosive cyclogenesis over the west-central North Atlantic Ocean, 1981-84. Part I: Composite structure and mean behavior. Mon. Wea. Rev., 114, 1781-1794, https:// doi.org/10.1175/1520-0493(1986)114<1781:ECITWC $>2.0$. $\mathrm{CO} ; 2$.

Sasaki, Y. N., and N. Schneider, 2011: Interannual to decadal Gulf Stream variability in an eddy-resolving ocean model. Ocean Modell., 39, 209-219, https://doi.org/10.1016/ j.ocemod.2011.04.004.

Simonnet, E., M. Ghil, K. Ide, R. Temam, and S. Wang, 2003: Lowfrequency variability in shallow-water models of the winddriven ocean circulation. Part II: Time-dependent solution. J. Phys. Oceanogr., 33, 729-752, https://doi.org/10.1175/1520-0485 (2003)33<729:LVISMO > 2.0.CO;2.

,-- , and H. Dijkstra, 2005: Homoclinic bifurcations in the quasi-geostrophic double-gyre circulation. J. Mar. Res., 63 , 931-956, https://doi.org/10.1357/002224005774464210.

Smith, P. C., R. W. Houghton, R. G. Fairbanks, and D. G. Mountain, 2001: Interannual variability of boundary fluxes and water mass properties in the Gulf of Maine and on Georges Bank: 1993-1997. Deep-Sea Res. II, 48, 37-70, https:// doi.org/10.1016/S0967-0645(00)00081-3.

Spall, M. A., 1996: Dynamics of the Gulf Stream/deep western boundary current crossover. Part II: Low-frequency internal 
oscillations. J. Phys. Oceanogr., 26, 2169-2182, https://doi.org/ 10.1175/1520-0485(1996)026<2169:DOTGSW >2.0.CO;2.

Stephenson, D. B., V. Pavan, and R. Bojariu, 2000: Is the North Atlantic Oscillation a random walk? Int. J. Climatol., 20, 1-18, https:// doi.org/10.1002/(SICI)1097-0088(200001)20:1<1::AID-JOC456>3.0 CO;2-P.

Sutton, R. T., and M. R. Allen, 1997: Decadal predictability of North Atlantic sea surface temperature and climate. Nature, 388, 563-567, https://doi.org/10.1038/41523.

Taylor, A. H., and J. A. Stephens, 1980: Latitudinal displacements of the Gulf Stream (1966 to 1977) and their relation to changes in temperature and zooplankton abundance in the $\mathrm{NE}$ Atlantic. Oceanol. Acta, 3, 145-149.

, and _- 1998: The North Atlantic Oscillation and the latitude of the Gulf Stream. Tellus, 50A, 134-142, https://doi.org/ 10.3402/tellusa.v50i1.14517.

- and A. Gangopadhyay, 2001: A simple model of interannual displacements of the Gulf Stream. J. Geophys. Res., 106, 13 849-13 860, https://doi.org/10.1029/1999JC000147.

, M. B. Jordan, and J. A. Stephens, 1998: Gulf Stream shifts following ENSO events. Nature, 393, 638, https://doi.org/ $10.1038 / 31380$.
Thomson, D. J., 1982: Spectrum estimation and harmonic analysis. Proc. IEEE, 70, 1055-1096, https://doi.org/10.1109/ PROC.1982.12433.

Vimont, D., 2015: Meridional mode website. University of Wisconsin-Madison, accessed 2 June 2017, http://www.aos. wisc.edu/ dvimont/MModes/Home.html.

von Storch, H., and F. W. Zwiers, 1999: Statistical Analysis in Climate Research. Cambridge University Press, 484 pp.

Watanabe, M., M. Kimoto, T. Nitta, and M. Kachi, 1999: A comparison of decadal climate oscillations in the North Atlantic detected in observations and a coupled GCM. J. Climate, 12, 2920-2940, https://doi.org/10.1175/1520-0442(1999)012<2920: $\mathrm{ACODCO}>2.0 . \mathrm{CO} ; 2$.

Watelet, S., J.-M. Beckers, and A. Barth, 2017: Reconstruction of the Gulf Stream from 1940 to the present and correlation with the North Atlantic Oscillation. J. Phys. Oceanogr., 47, 2741-2754, https://doi.org/10.1175/JPO-D-17-0064.1.

Wunsch, C., 1999: The interpretation of short climate records, with comments on the North Atlantic and Southern Oscillations. Bull. Amer. Meteor. Soc., 80, 245-255, https:// doi.org/10.1175/1520-0477(1999)080<0245:TIOSCR >2.0. $\mathrm{CO} ; 2$. 